\title{
Replacement of Synaptic Terminals in Lamina II and Clarke's Nucleus after Unilateral Lumbosacral Dorsal Rhizotomy in Adult Cats
}

\author{
Marion Murray and Michael E. Goldberger \\ Department of Anatomy, The Medical College of Pennsylvania, Philadelphia, Pennsylvania 19129
}

Evidence from previous light-microscopic studies suggested that lumbosacral dorsal rhizotomy in cats elicits sprouting of converging undamaged systems into partially deafferented Clarke's nucleus and lamina II. We therefore applied quantitative electron-microscopic methods to determine whether this sprouting is associated with replacement of synaptic terminals (reactive reinnervation). We used stereological and morphometric methods to estimate terminal number per cross section in right and left lamina II and Clarke's nucleus in adult cats after acute and chronic unilateral (right-sided) lumbosacral deafferentation. Planimetric measurements of area indicated no significant shrinkage of either region as a result of the deafferentation; an increase in area occupied by glial cytoplasm (gliosis) equaled the decrease occupied by axonal components. The gliosis appears to persist indefinitely, although the degenerative debris stainable with conventional light-microscopic methods does not persist. Analysis of the synaptic population of lamina II reveals that the large central or "scalloped" terminals comprise a substantial fraction $(>\mathbf{4 0 \%})$ of the total area occupied by terminals in control material and that this population is largely lost upon deafferentation, leaving a large population of small terminals with spherical vesicles. Nevertheless, estimates of total terminal number indicate no difference between control and deafferented lamina II, suggesting a rapid and virtually complete replacement of lost dorsal root terminals by small terminals containing spherical vesicles. Terminal number in Clarke's nucleus also remains constant despite the loss of the dorsal root input. We conclude that there is also a virtually complete and rapid replacement of lost terminals in Clarke's nucleus by terminals containing spherical vesicles. These data provide an example of a case in which axonal sprouting demonstrated with light-microscopic methods is associated with electron-microscopic evidence of reactive reinnervation.

Although collateral sprouting by intact axons in response to damage has been described in many parts of the adult brain (see Cotman et al., 1981, for review; Chen and Hillman, 1982; Murakami et al., 1982), sprouting in the spinal cord remains controversial. It has been reported by some investigators (see Goldberger and Murray, 1978, 1985, for reviews; Liu and Chambers,

\footnotetext{
Received July 11, 1985; revised Mar. 17, 1986; accepted Mar. 24, 1986.

The invaluable and expert technical help provided by Wendy Battisti and Theresa Eckenrode is gratefully acknowledged. Some of this work was carried out at the National Defense Medical College, Taipei, Taiwan, Republic of China, while M.M. was a Visiting Professor in the Department of Anatomy. Their help and support is also greatly appreciated. Edith Paige, Joe Olivier, and Alan Tessler also contributed to this effort. This work was supported by Research Grants NS-16556 (M.M.) and NS-16629 (M.G.) of the National Institutes for Neurological and Communicative Disorders and Stroke and the Medical Rescarch Service of the Veterans Administration (AT).

Correspondence should be addressed to Marion Murray, Department of Anatomy, The Medical College of Pennsylvania, 3200 Henry Avenue/EPPI Division, Philadelphia, PA 19129
}

Copyright (C) 1986 Society for Neuroscience $0270-6474 / 86 / 113205-13 \$ 02.00 / 0$
1958; Pullen and Sears, 1978, 1983; Tessler et al., 1981; Thor et al., 1982, 1986) and denied by others (Rodin and Kruger, 1984; Rodin et al., 1983; Wall, 1984). Reports that sprouting cannot be demonstrated after some central lesions (Devor et al., 1986; Kerr, 1972; Rodin and Kruger, 1984; Rodin et al., 1983) imply either that specific regulatory influences exist that determine the success or failure of sprouting (Goldberger and Murray, 1978,1985 ) or that positive evidence for sprouting is artefactual (Rodin and Kruger, 1984; Rodin et al., 1983; Wall, 1984). This issue needs to be resolved since sprouting has important theoretical implications for growth and specificity of projections in the mature CNS and also as a possible mechanism underlying recovery of function (see Cotman et al., 1981; Goldberger, 1981).

Several factors have made studies of sprouting difficult to interpret: (1) The demonstration of sprouting usually depends upon some labeling method: degeneration staining methods (Goldberger and Murray, 1974, 1978; Kerr, 1972; Stelzner et al., 1979), axonal transport of newly synthesized proteins (Loesche and Steward, 1977; Murray and Goldberger, 1974), or HRP (Rodin et al., 1983; Thor et al., 1982); or immunocytochemical staining of axons and terminals (Gage et al., 1983; Tessler et al., 1981). None of these methods can be assumed to be amenable to a quantitative analysis of the entire population of axons that may sprout. (2) Since some of these methods depend upon metabolic properties of the neurons investigated, increased labeling due to sprouting may be confounded with increases that reflect metabolic changes. (3) Denervated regions in which sprouting is investigated are likely to undergo shrinkage. Regions must be chosen for study, therefore, that have relatively clear boundaries in order that corrections can be made for lesion-induced changes in volume. (4) Although specific labeling methods reveal a particular system, they do not provide information about other converging systems. Negative results may simply indicate that, of a number of systems projecting to a partially denervated region, the ones that sprout are not the ones under examination (Goldberger and Murray, 1978). Even within the same system, some axons exhibit a greater propensity to sprout than others (Jackson and Diamond, 1983; Mendell et al., 1986). A different approach to assessing lesion-induced changes is to examine the consequences of the lesion for the entire synaptic population in the target zone. An absence of sprouting should be manifested by a permanent decrease in the total synaptic population.

Synaptogenesis is not a necessary outcome of axonal sprouting (Chow et al., 1981), and light-microscopic methods that have demonstrated increases in a projection pattern do not provide evidence that newly sprouted axons have made synaptic contacts. In certain regions of the CNS, however, sprouting has been shown to result in replacement of synaptic terminals (reactive reinnervation) (Chen and Hillman, 1982; Murakami et al., 1982; Pullen and Sears, 1983; Raisman, 1969), whose functional capacity has been studied in some cases (Pullen and Sears, 1978, 1983; Tsukahara, 1978; Tsukahara et al., 1975) but not 
others (Chen and Hillman, 1982; Raisman, 1969). In some systems, lesions that elicit partial denervation followed by sprouting have been shown to elicit functional deficits followed by considerable recovery of function. The recovery may be demonstrated by behavioral (Goldberger and Murray, 1978; Loesche and Steward, 1977) or neurophysiological (Pubols and Goldberger, 1980; Tsukahara, 1978; Tsukahara et al., 1975) assays, and it seems reasonable to suggest that this recovery is mediated, at least in part, by sprouting axons. Nevertheless, demonstration of synaptic replacement following lesions is a necessary step before it can be concluded that sprouting is associated with formation of new synaptic contacts and, therefore, that sprouting contributes to recovery of function.

The aim of the present study was to determine if synaptogenesis occurred in a system in which both light-microscopic evidence for sprouting and behavioral evidence for recovery of function have been described. The model chosen was the cat spinal cord partially deafferented by unilateral complete lumbosacral dorsal rhizotomy and/or ganglionectomy. The advantages of this model are (1) there is light-microscopic (Goldberger and Murray, 1978; Goldberger et al., 1985; Tessler et al., 1980, 1981) and biochemical (Tessler et al., 1984) evidence for sprouting after this lesion; (2) the cat spinal cord contains several regions with well-defined houndaries that are suitable for measurement to control for shrinkage; (3) extradural rhizotomy does not damage systems other than the dorsal roots and therefore does not elicit other kinds of compensatory growth, e.g., pruning (see Pickel et al., 1974; Schneider, 1970); (4) dorsal rhizotomy in cats results in an unambiguous behavioral deficit followed by an equally obvious recovery of function (Goldberger, 1977).

The specific areas we have examined were lamina II at $\mathrm{L}_{6}$ and Clarke's nucleus at $\mathrm{L}_{3}$. The dorsal root projection to lamina II is primarily segmental and that to Clarke's nucleus an ascending but topographic projection (Szentagothai, 1961); a complete lumbosacral dorsal rhizotomy will therefore result in maximal denervation of lamina II in caudal lumbar segments and of Clarke's nucleus in rostral lumbar segments. We applied quantitative electron-microscopic methods in order to estimate the number of terminals in lamina II and Clarke's nucleus after complete lumbosacral dorsal rhizotomy and/or ganglionectomy in control and partially deafferented spinal cords. We provide evidence that the normal number of terminals is conserved, that the replacement of lost terminals begins soon after the deafferentation and is virtually complete, and that the replaced terminals share some morphological characteristics with those that were lost. Some of these results have appeared in preliminary form (Murray ct al., 1983, 1984).

\section{Materials and Methods}

Thirteen adult cats were anesthetized with Nembutal. Unilateral (rightsided) lumbosacral dorsal rhizotomies (L1-S2) and, in most cases, ganglionectomies were performed extradurally under antiseptic conditions according to methods described elsewhere (Goldberger and Murray, 1974). For convenience, the side on which the rhizotomy was performed is referred to as the "deafferented" side, although afferents from many sources remain. All animals were examined postoperatively for the presence of tendon reflexes and responses to intense pinching in order to eliminate any animal with an incomplete lesion. Animals were allowed to survive for acute $(2.5,3,4,4,6,6 \mathrm{~d})$ and chronic $(3,3,9,12,15$ months) periods. Two of the chronic animals were studied behaviorally, and the recovery of function was documented (Goldberger and Olivier, 1984). In addition to the unoperated side of the experimental animals' spinal cords, 1 unoperated spinal cord was used as a control. One deafferented animal with a survival period of 12 months was perfused with $10 \%$ formalin and the L6 segment was studied for persistence of degenerative debris using a silver stain (Ebbesson and Rubenson, 1969). At sacrifice, the other animals were deeply anesthetized, injected intravenously with $1 \mathrm{cc}$ of $10 \%$ heparin and $20 \mathrm{~min}$ later with $1 \% \mathrm{NaNO}$ intubated, and artificially respired, and then perfused intracardially with saline followed by $0.5 \%$ glutaraldehyde and $4 \%$ paraformaldehyde in phosphate buffer $(0.1 \mathrm{M}$ final molarity). The spinal cord was removed and the L6 and L3 segments were sliced into cross sections. The left (control) and right (deafferented) dorsal horns of L6 were dissected out. For the L3 segment, single blocks were prepared that contained both control and deafferented Clarke's nuclei. These blocks were osmicated and embedded in a mixture of epon and araldite.

Cross sections, $1 \mu \mathrm{m}$ thick, were cut with glass knives and stained with toluidine blue. Camera lucida drawings were made of the sections, the boundaries of lamina II and Clarke's nucleus were outlined, and the areas measured planimetrically. The cross-sectional area was measured from 2-7 sections taken from each nucleus and lamina on control sides and from sides that had been deafferented 3-6 d (acute) and 3-15 months (chronic) previously. The mean cross-sectional area of the nucleus or lamina was then calculated for individual cases and for control, acutely deafferented and chronically deafferented groups. The boundaries of Clarke's nucleus were readily recognized owing to the different density of the neuropil between Clarke's nucleus and surrounding neuropil. The criteria for defining the lamina I-II and lamina II-III boundaries in control and deafferented spinal cords were similar to those described by others (Ralston, 1968; Ralston and Ralston, 1979; Snyder, 1982). Lamina I could readily be recognized by the presence of marginal neurons, bundles of myelinated fibers cut in cross section, and the greater density of neuropil. The lamina II-III boundary was quite irregular but could be demarcated primarily on the basis of the denser neuropil imparted by the presence of small myelinated axons. The boundaries between laminae and between Clarke's nucleus and adjacent neuropil that were identified by one investigator could be recognized independently by another investigator on both control and deafferented sides.

\section{Stereological analysis}

Thin sections, which contained an entire lamina II or both Clarke's nuclei, were cut, placed on 400 mesh grids (Pelco), stained, and the sections examined in a JEOL 100 S EM. At low magnification, the sections were outlined on graph paper, and, using landmarks on the adjacent semithin section as a reference, the laminar or nuclear boundaries were identified. The nucleus or lamina was systematically traversed and 1-2 photographs at a magnification of $8000 \times$ were taken from alternate grid squares. Only grid squares in which more than one-half of the field was occupied by large blood vessels or by the large bundles of myelinated axons that penetrate the medial dorsal horn were excluded from the photographic survey. Some 20-30 photographs were routinely taken from each nucleus or lamina.

Photomicrographs were enlarged $2.5 \times$. All micrographs were analyzed stereologically by 2 independent investigators. The area fractions occupied by axons (myelinated, unmyelinated, degenerating), terminals, cell bodies and dendrites, and non-neuronal structures (glia, small blood vessels, and unidentified profiles) were calculated. For the stereological analysis, a profile was identified as a terminal if it contained a cluster of 5 or more synaptic vesicles. The identification of small processes was more difficult. We considered profiles with pale cytoplasmic matrix, containing cytoskeletal elements, which were circular in cross section or of constant caliber if cut longitudinally, to be unmyelinated axons. Profiles that were more irregular in shape and contained pale cytoplasmic matrix were classified as dendrites. Processes were counted as glial profiles if they were irregular in shape or contained glial filaments or a dense cytoplasmic matrix. Profiles identified as glial accounted for the vast majority ( $>95 \%$ area fraction) of the non-neuronal structures. Two to 3 sections were analyzed per nucleus or lamina in most cases and the results were averaged. The correlation between results of the stereological analysis performed by the 2 investigators was consistently high $(r=0.98)$.

\section{Morphometric analysis}

Terminals from randomly selected photomicrographs were then analyzed morphometrically. For the morphometric analysis, a profile was considered to be a synaptic terminal if it contained a cluster of 5 or more synaptic vesicles and contacted neuronal profiles with a recognizable postsynaptic density. The cross-sectional area and the perimeter: area ratio of each terminal were measured planimetrically. The length of the postsynaptic density was measured separately for $20-50$ terminals from each nucleus or lamina. The terminal was classified as being intact or degenerating; the synaptic vesicles were classificd as bcing spherical, pleomorphic, or containing a dense core. The number of postsynaptic densities contacted by each terminal profile was counted, 

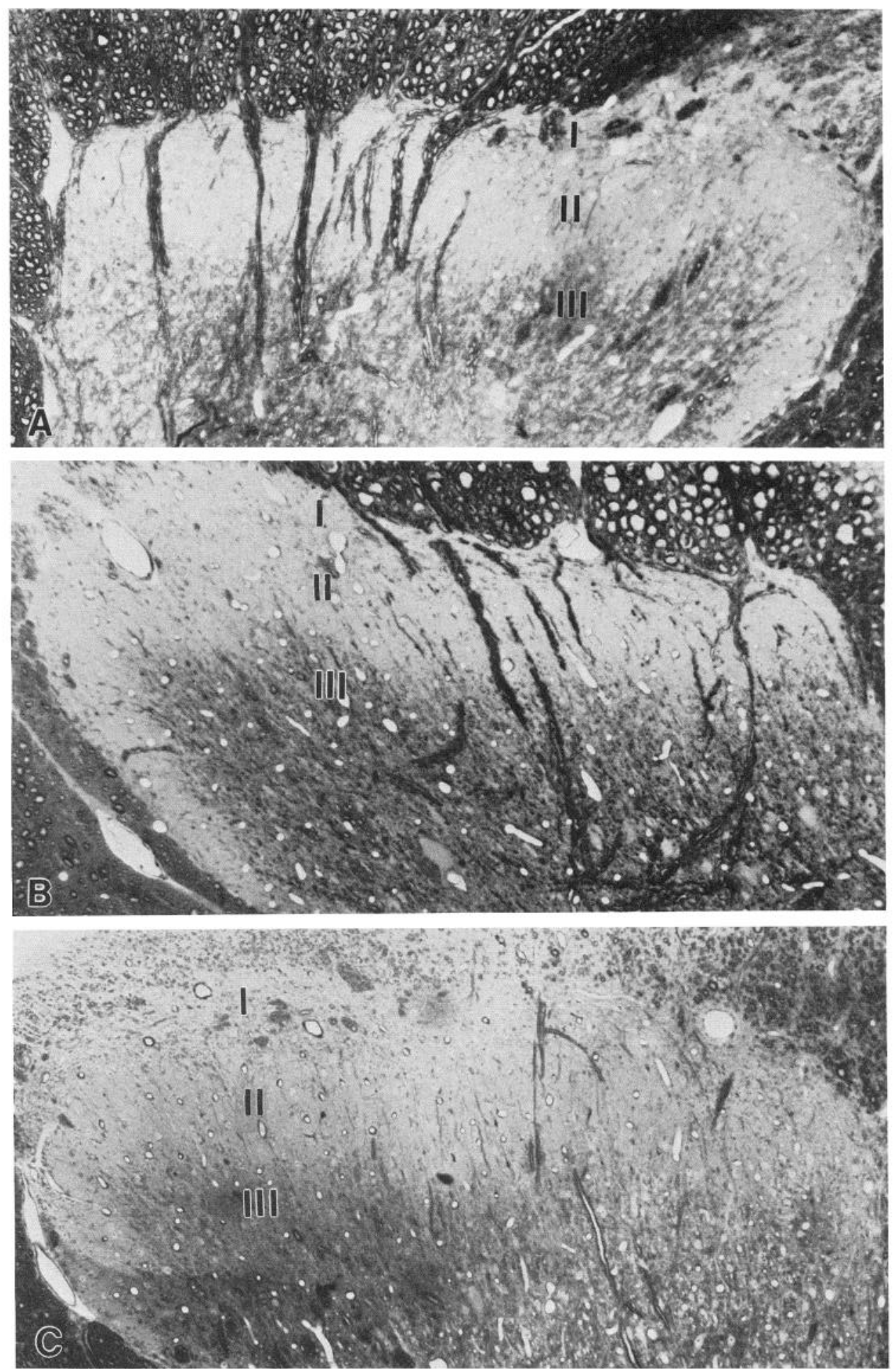

Figure 1. Cross sections of semithin sections from dorsal horn of cat, stained with toluidine blue. The neuropil of lamina II is less dense than the neuropil of laminae I and III. $\times 100$. $A$, Control side. Lamina I is recognized by small bundles of fibers cut in cross section. Laminae I, II, and III boundaries are defined microscopically by different densities of the neuropil imparted by myelinated axons. $B$, Deafferented side, $4 \mathrm{~d}$ survival. Myelinated axons in the dorsal columns and penetrating the dorsal horn are undergoing degeneration. The boundaries between laminae I, II, and III can still be recognized microscopically. $C$, Deafferented side, 7 months survival. Myelinated axons in the dorsal columns and some in laminae I, II, and III have degenerated, including the bundles of axons penetrating the dorsal horn. The remaining myelinated axons from intraspinal sources impart a greater density to laminae I and III than lamina II, and these boundaries can be recognized microscopically by carefully focusing through the section. and a mean multisynaptic index (mean number of contacts with separate postsynaptic structures per terminal profile) was calculated.

An estimate of total number of terminals per cross section was calculated for each nucleus or lamina as follows:

Total number of terminals per cross section

$$
=\frac{\begin{array}{c}
\text { Cross-sectional area of } \\
\text { nucleus or lamina }\left(\mu \mathrm{m}^{2}\right)
\end{array} \times \begin{array}{c}
\% \text { area occupied by terminal } \\
\text { profiles (stereological analysis) }
\end{array}}{\text { Mean cross-sectional area of }}
$$

[Total number of synaptic contacts per cross section of lamina II] = [Multisynaptic index] $\times$ [Total number of terminals per cross section].
The group mean total terminal or synaptic number was then calculated for control and acutely and chronically deafferented nuclei or laminae. All comparisons were tested statistically using 1-way analysis of variance and Fisher's least-significant difference test $(p<0.05$; NCSS statistical package).

\section{Results \\ Lamina II}

Cross-sectional area of lamina II

The cross-sectional area of lamina II was measured from camera lucida drawings of sections taken from control and deafferented 
Table 1. Cross-sectional area of lamina II

\begin{tabular}{lll} 
Group & $n$ & $\begin{array}{l}\text { Laminar area } \\
\left(\mu \mathrm{m}^{2} \times 10^{4}\right)\end{array}$ \\
\hline Control & 8 & $19.2 \pm 1.3$ \\
Acute deafferentation & 4 & $17.8 \pm 1.4$ \\
Chronic deafferentation & 3 & $19.7 \pm 1.2$ \\
\hline
\end{tabular}

sides. Some distortion of the shape of the dorsal horn could be seen after chronic deafferentation (Fig. 1). Planimetric measurements indicate no significant shrinkage of the deafferented lamina II in either the acute or chronic survivors (Table 1).

\section{Stereological analysis}

A summary of the stereological analysis of lamina II for the control and acute and chronic deafferented groups is shown in Table 2 and Figure 2. After chronic deafferentation, there is a decrease in the area occupied by myelinated axons and by terminals compared to control values. There is also a statistically significant increase in area occupied by non-neuronal elements (primarily glial cytoplasm), which is detectable in both acutely and chronically deafferented lamina II. This increase in glial cytoplasm is equivalent to the loss in myelinated axons and terminals in the deafferented lamina II and accounts for the absence of measurable shrinkage and the maintenance of normal laminar dimensions. Degenerative debris was most common in the earliest postoperative period examined $(2.5 \mathrm{~d})$ but had virtually disappeared from lamina II neuropil by $6 \mathrm{~d}$ postoperatively. Degenerating myelinated axons could be recognized in the white matter on the deafferented side for longer periods, up to 3 months postoperatively. Sections stained by silver methods (Ebbesson and Rubinson, 1969) for degenerating axons from deafferented cats with 12 month survival periods were examined. No stainable degenerative debris could be seen in the gray matter, despite the persistence of gliosis at this timc (Fig. 3). The gliosis in lamina II, unlike the argyrophilic degeneration products, appears to remain indefinitely. Other components of the neuropil, the unmyelinated axons, and postsynaptic structures show no significant changes from control levels. Degenerative debris was never seen in lamina II on the unoperated control side. No differences were seen between unoperated sides of deafferented animals and the unoperated control animal. (One animal was killed 2.5 d postoperatively; lamina II on the deafferented side contained some degenerating axons and terminals but was quantitatively similar to control animals. The data for this animal are not included in the tables.)

\section{Synaptic terminals in lamina II}

A summary of the characteristics of terminals in control and deafferented lamina II is shown in Table 3.

Control. Most of the synaptic terminals in control lamina II contain spherical vesicles $(87 \%)$ and make contacts with dendritic processes (98\%; Table 3). Within this population, it is possible to recognize 2 subtypes: $84 \%$ of these profiles are small and make a single synaptic contact upon a single postsynaptic structure. About 16\% are larger, contain somewhat more densely

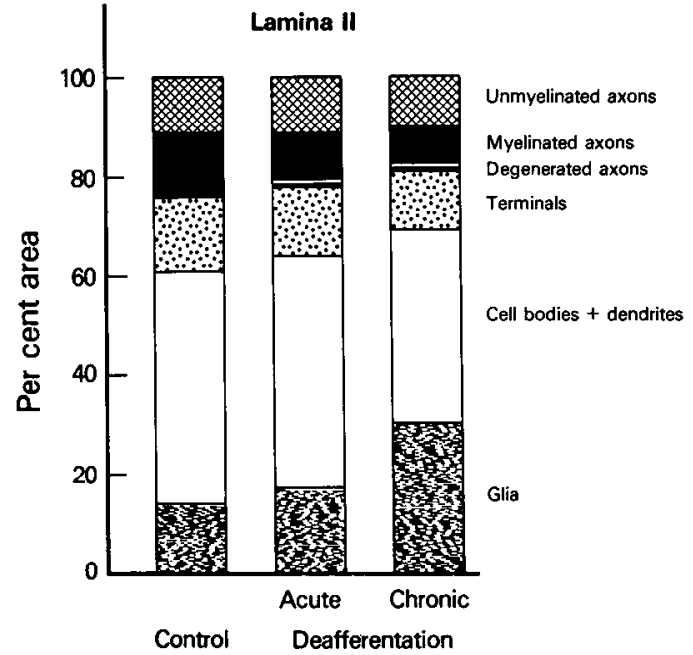

Figure 2. Composition of neuropil. Histogram summarizing stereological data from lamina II. Bars indicate composition of neuropil in control and acute and chronic deafferentation groups. Since there was no difference in mean cross-sectional area of lamina II among the groups, each bar is set equal to $100 \%$. Bars are divided according to the area fraction occupied by axons, terminals, postsynaptic structures, and glia. Note decreased area fraction occupied by myelinated axons in the chronically deafferented group and the increase in glial fraction in both acute and chronically deafferented groups compared to controls. Area occupied by terminals is also decreased in the deafferented groups.

packed spherical vesicles, and make 2 or more synaptic contacts upon different postsynaptic profiles (Fig. $4 A$ ). The terminals that make multiple contacts have been called central or "scalloped" terminals and are thought to originate largely or entirely from dorsal root afferents (Coimbra et al., 1974; Knyihar and Csillik, 1976; Ralston and Ralston, 1979; Ribeiro-da-Silva and Coimbra, 1984; Snyder, 1982). The central terminals arc distributcd evenly mediolaterally across the lamina. The mean surface area of terminals with multiple contacts is 3.8 times larger in area than the area of those which make single contacts (Wu et al., 1986). Although comprising only $16 \%$ of the total number of terminals, these large central terminals account for more than $40 \%$ of the total area occupied by axonal terminals in control lamina II.

Acute. Following deafferentation, only a small number of dark degenerating profiles were seen, most frequently at the earliest survival period examined $-2.5 \mathrm{~d}$ (Fig. $4, B, C$ ). This observation is consistent with other reports (Heimer and Wall, 1968; Ralston, 1968) that the dense type of degeneration is uncommon after deafferentation and that it is usually seen at early postoperative times. All degenerating terminals that could be classified contained spherical vesicles. Both large central and smaller terminals degenerated (Fig. 4, $B, C$ ).

Chronic. At later postoperative periods, stereological analysis indicates a decrease in total area occupied by terminals. Very few terminals are seen that make more than 1 synaptic contact at this time. These observations are borne out by the quantitative analysis which demonstrates a significant decrease in the

Table 2. Composition of lamina II ( $\%$ of area)

\begin{tabular}{|c|c|c|c|c|c|c|c|}
\hline Group & $n$ & $\begin{array}{l}\text { Myelinated } \\
\text { axons }\end{array}$ & $\begin{array}{l}\text { Unmyelinated } \\
\text { axons }\end{array}$ & $\begin{array}{l}\text { Degenerated } \\
\text { axons }\end{array}$ & Terminals & $\begin{array}{l}\text { Perikarya, } \\
\text { dendrites }\end{array}$ & $\begin{array}{l}\text { Non-neuronal } \\
\text { structures }\end{array}$ \\
\hline Control & 10 & $12.1 \pm 1.6$ & $11.9 \pm 1.7$ & 0 & $14.5 \pm 0.7$ & $47.3 \pm 2.1$ & $14.0 \pm 1.6$ \\
\hline Acute deafferentation (3-6 d p.o.) & 5 & $10.0 \pm 2.1$ & $11.9 \pm 1.5$ & $2.0 \pm 0.9^{a}$ & $12.3 \pm 1.1$ & $45.8 \pm 3.7$ & $17.8 \pm 1.4^{a}$ \\
\hline Chronic deafferentation (3-15 mo. p.o.) & 5 & $8.4 \pm 0.9 a$ & $10.4+3.8$ & $0.9 \pm 0.5^{a}$ & $11.0+0.9^{a}$ & $44.0+3.5$ & $25.2 \pm 2.7^{a}$ \\
\hline
\end{tabular}

Means \pm SEM are given.

a Significantly different from control $(p<0.05)$ 

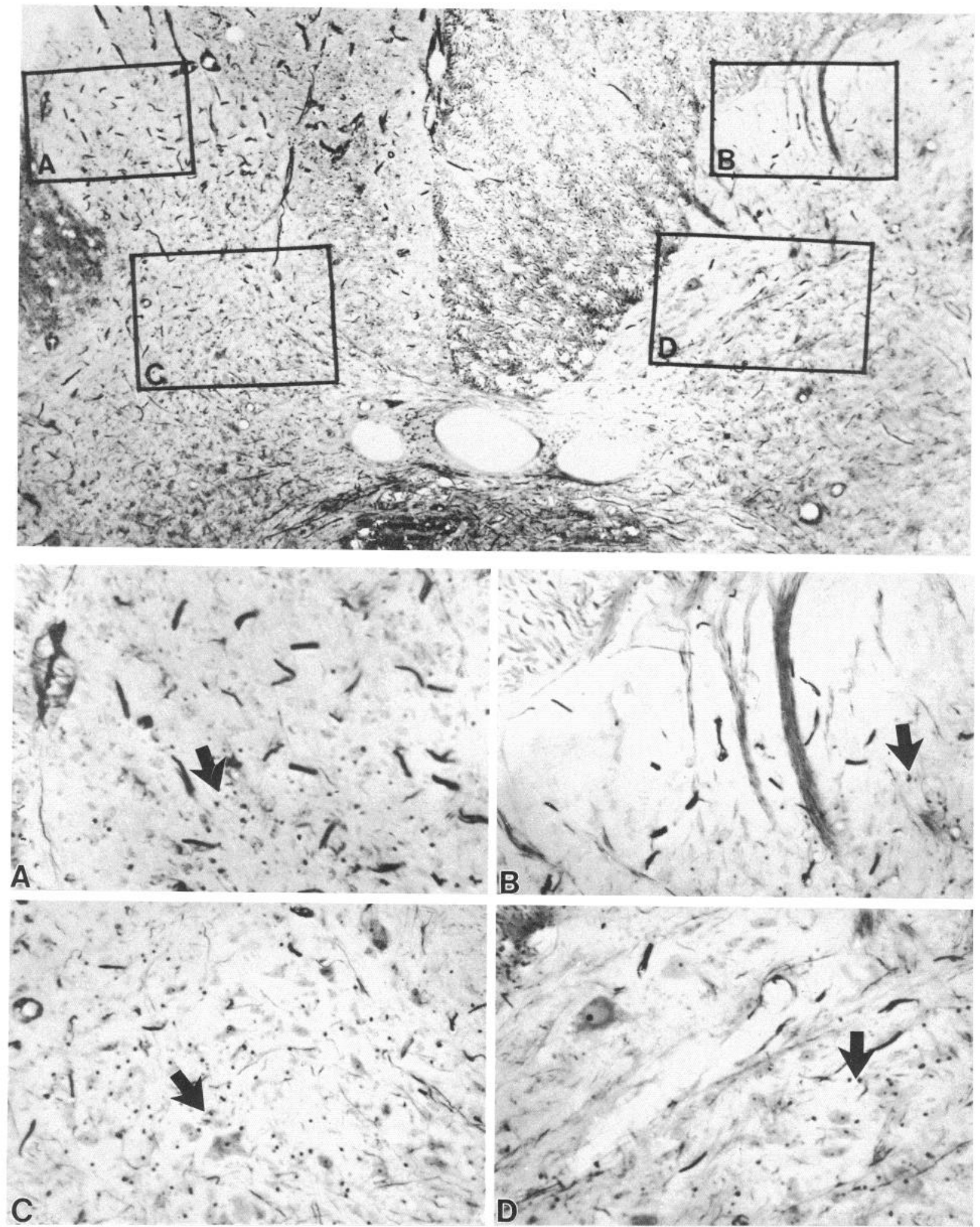

Figure 3. Section from L6 dorsal horn on the deafferented $(A, C)$ and control $(B, D)$ sides from an animal with a 12 month survival period, stained with the Ebbesson-Rubinson modification of the Nauta method. $A$ and $B$, Dorsal horn; $C$ and $D$, intermediate zone of the spinal cord. Note increased number of glial nuclei on the deafferented sides $(A, C)$ compared to comparable regions on the control sides $(B, D)$. There is no recognizable degenerative debris present at this postoperative period. Closed arrows indicate glial nuclei. Open arrows indicate normal axons. $\times 200$.

mean area of terminals and in the multisynaptic index (Table 3 ). These data are consistent with the permanent loss of virtually all central terminals, as well as a loss of some of the smaller terminals. Other characteristics of synaptic contacts-i.e., the percentage of terminals containing each vesicle type; the percentage of axosomatic, axodendritic, and axoaxonic contacts; the perimeter: area ratio; and the lengths of postsynaptic densities-showed no significant differences between control and 

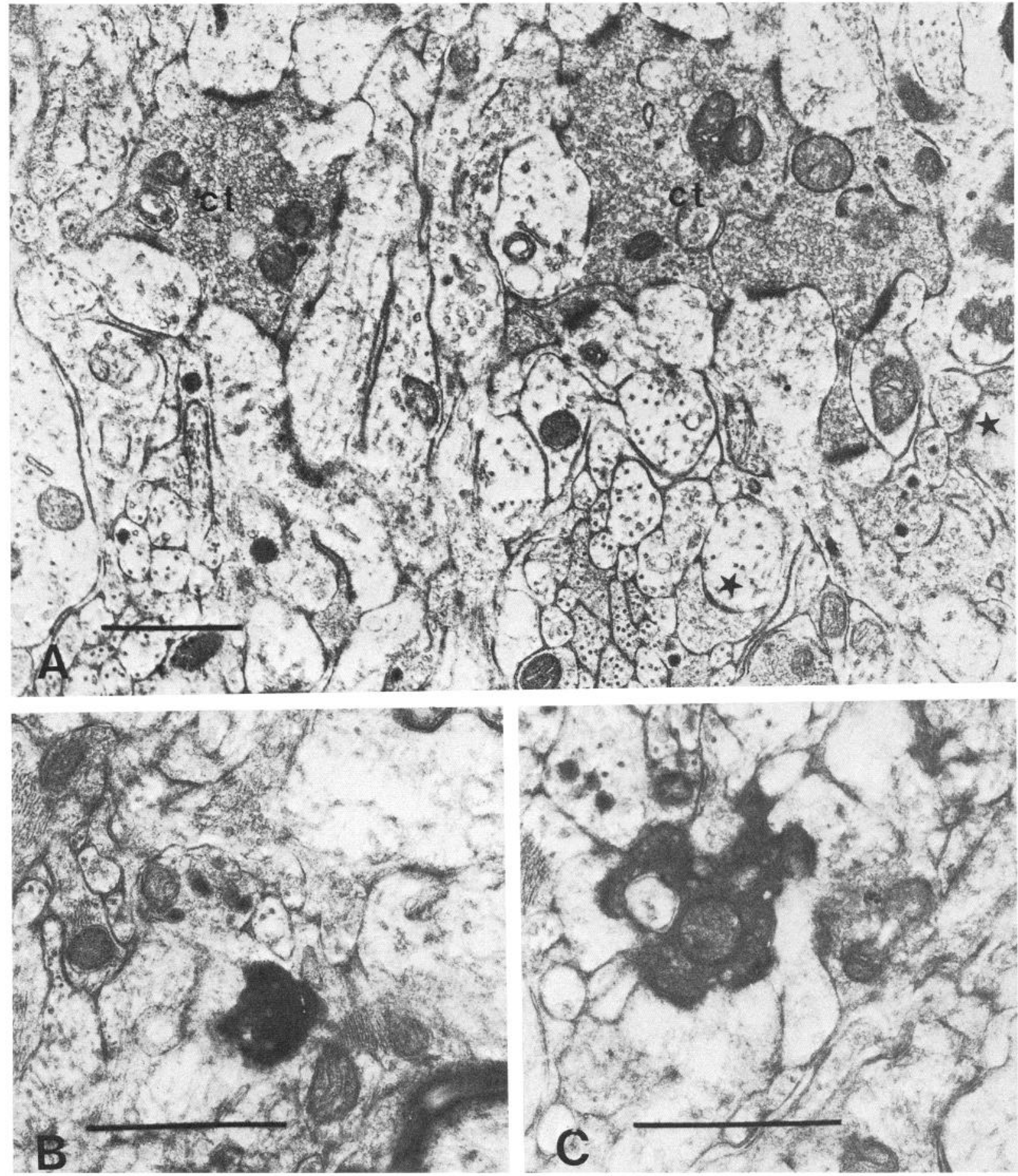

Figure 4. Electron micrographs showing synaptic contacts in lamina II. Calibration bar, $1 \mu \mathrm{m}$. $A$, Example of central terminal (ct) that contains spherical vesicles and makes several asymmetric contacts upon different dendritic profiles and small conventional terminals ( $\star$ ) containing spherical vesicles and making asymmetric contacts upon dendritic profiles. Electron micrograph by Dr. Liang-Fang Wu. $B$, Example of dense degeneration of a small terminal $2.5 \mathrm{~d}$ after lumbosacral dorsal rhizotomy. $C$, Example of dense degeneration of a central terminal $2.5 \mathrm{~d}$ after lumbosacral dorsal rhizotomy.

acute and chronic deafferented laminae. Changes in the 3-dimensional shape of terminals might not be detected by these methods. Unoccupied postsynaptic densities were not seen.

Number of terminals and synaptic contacts in lamina II Synaptic number in lamina II was estimated for each case and the group means were then computed. The estimated total num- ber of terminals per cross section of lamina II (Table 4) shows no difference among control, acutely or chronically deafferented laminae. Since the population of central terminals normally accounts for a large fraction of the total area occupied by terminals and is virtually eliminated in the deafferented laminae, these data suggest that the conservation of terminal number results from the rapid replacement of central terminals by small- 


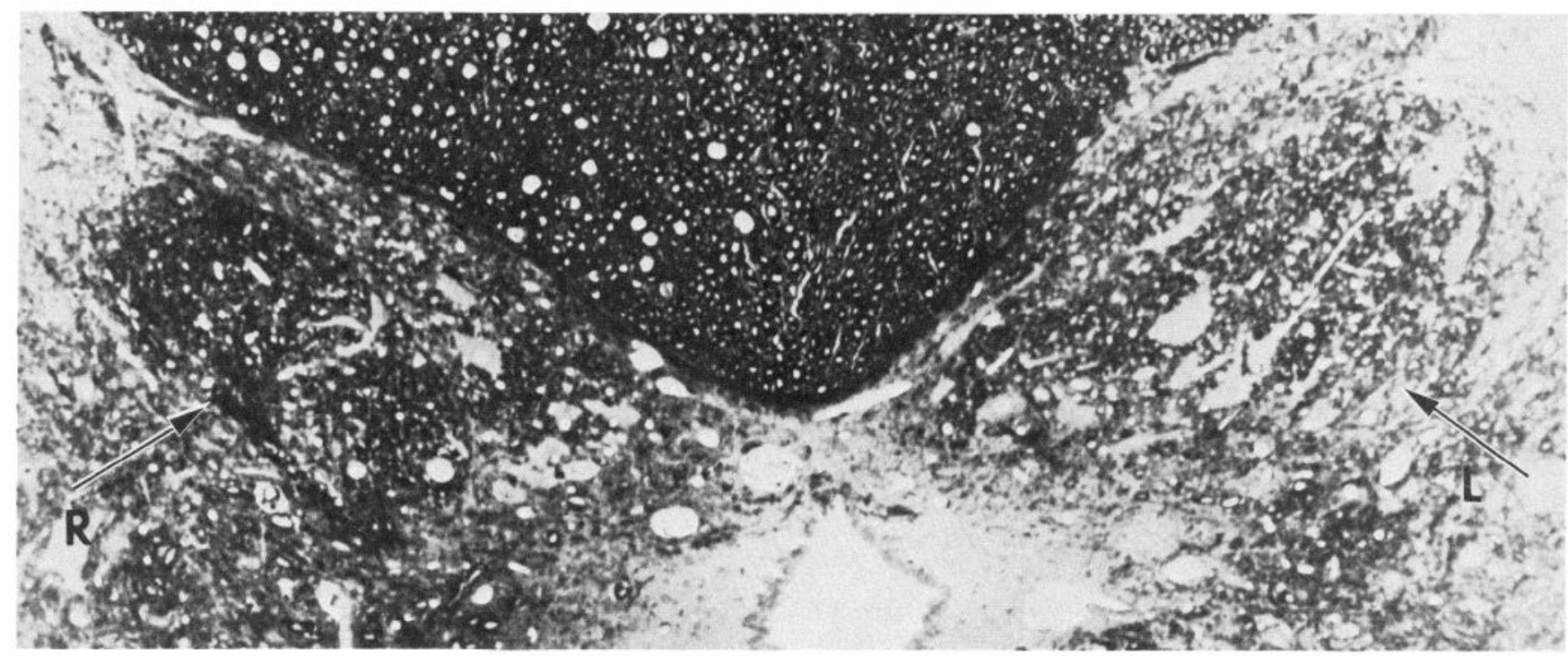

Figure 5. Semithin toluidine blue-stained section of control (left) and deafferented (right) Clarke's nuclei $4 \mathrm{~d}$ after right lumbosacral deafferentation. Boundaries of both nuclei can be recognized. $\times 150$.

er terminals that make fewer synaptic contacts. When the total number of synaptic contacts in lamina II is calculated (multiplying the number of terminals by the mean synaptic index), then the chronically deafferented lamina shows a decreased number of contacts compared to controls (Table 4). These data suggest that the number of terminals is conserved but that reinnervation is incomplete and therefore that some postsynaptic structures still remain partially denervated.

\section{Clarke's nucleus}

Cross-sectional area of Clarke's nucleus

Degeneration stains indicated that dorsal roots normally project densely to fill the morphologically defined boundaries of Clarke's nucleus. Planimetric measurements, however, show that there is no significant difference in cross-sectional area due to deafferentation (Fig. 5, Table 5).

\section{Stereological analysis}

The stereological analysis (Table 6, Fig. 6) demonstrates that Clarke's nucleus differs in several predictable respects from lamina II (Fig. 2, Table 2). A larger area fraction is occupied by myelinated than unmyelinated axons, consistent with the dense projection of group I and II axons to Clarke's nucleus, and a smaller fraction of the area is occupied by synaptic terminals, consistent with less synaptic input compared to lamina II. Acutely and chronically after deafferentation there is a significant decrease in the area occupied by myelinated axons, and a parallel increase in the area occupied by glial cytoplasm. As in lamina II, the increase in glial cytoplasm is equivalent to the loss of axons and accounts for the absence of shrinkage. The area occupied by terminals is decreased only in the acutely deafferented Clarke's nucleus.

\section{Synaptic terminals in Clarke's nucleus}

Control. Three classes of terminals have been distinguished in Clarke's nucleus (Rethelyi, 1970): large terminals containing spherical vesicles ("giant" axon terminals; Fig. $7 B$ ) and 2 smaller terminal types (Fig. $7 A$ ), one containing spherical vesicles and another containing pleomorphic vesicles. In control Clarke's nucleus, about $80 \%$ of the terminals contain spherical vesicles and the remainder contain pleomorphic vesicles (Table 7). An examination of the size distribution of terminals with spherical vesicles, however, did not indicate that 2 populations of terminal profiles containing spherical vesicles, 1 giant and 1 small, could be distinguished on the basis of cross-sectional area (see also Tracey and Walmsley, 1984). Most terminal profiles contact only single postsynaptic structures in a cross section, although there may be more than one active zone per terminal profile.

Acute. Following deafferentation, dense degenerating termi-

Table 3. Synaptic terminals in lamina II

\begin{tabular}{|c|c|c|c|c|c|c|c|c|c|}
\hline \multirow[b]{3}{*}{ Group } & \multirow[b]{3}{*}{$n$} & \multirow[b]{3}{*}{$\begin{array}{l}\text { Terminal area } \\
\left(\mu \mathrm{m}^{2}\right)\end{array}$} & \multirow{3}{*}{$\begin{array}{l}\text { Mean } \\
\text { multisynaptic } \\
\text { index }\end{array}$} & \multicolumn{3}{|c|}{ Vesicle type (\%) } & \multirow{2}{*}{\multicolumn{3}{|c|}{ Postsynaptic structure (\%) }} \\
\hline & & & & & & Dense core & & & \\
\hline & & & & Spherical & Pleomorphic & $\begin{array}{l}\text { and } \\
\text { pleomorphic }\end{array}$ & $\begin{array}{l}\text { Axo- } \\
\text { dendritic }\end{array}$ & $\begin{array}{l}\text { Axo- } \\
\text { somatic }\end{array}$ & $\begin{array}{l}\text { Axo- } \\
\text { axonic }\end{array}$ \\
\hline Control & 8 & $0.966 \pm 0.092$ & $1.38 \pm 0.04$ & $87.0 \pm 6.9$ & $13.0 \pm 6.9$ & $6.7 \pm 3.9$ & $98.2 \pm 1.2$ & $1.4 \pm 1.4$ & $0.5 \pm 0.04$ \\
\hline \multicolumn{10}{|l|}{ Acute deafferentation } \\
\hline (3-6 d p.o.) & 4 & $0.776 \pm 0.058^{b}$ & $1.14 \pm 0.02^{b}$ & $88.5 \pm 4.3$ & $11.5 \pm 4.3$ & $4.3 \pm 0.3$ & $97.8 \pm 0.8$ & $2.0 \pm 1.2$ & $0.6 \pm 0.6$ \\
\hline \multicolumn{10}{|l|}{ Chronic deafferentation } \\
\hline (3-15 mo. p.o.) & 4 & $0.731 \pm 0.046^{b}$ & $1.14 \pm 0.02^{b}$ & $90.2 \pm 4.2$ & $9.7 \pm 4.2$ & $9.7 \pm 4.4$ & $97.1 \pm 1.7$ & $2.8 \pm 1.7$ & $1.0 \pm 0.4$ \\
\hline
\end{tabular}

Means \pm SEM are given.

${ }^{a}$ Mean cross-sectional area.

${ }^{b}$ Significantly different from control $(p<0.05)$. 


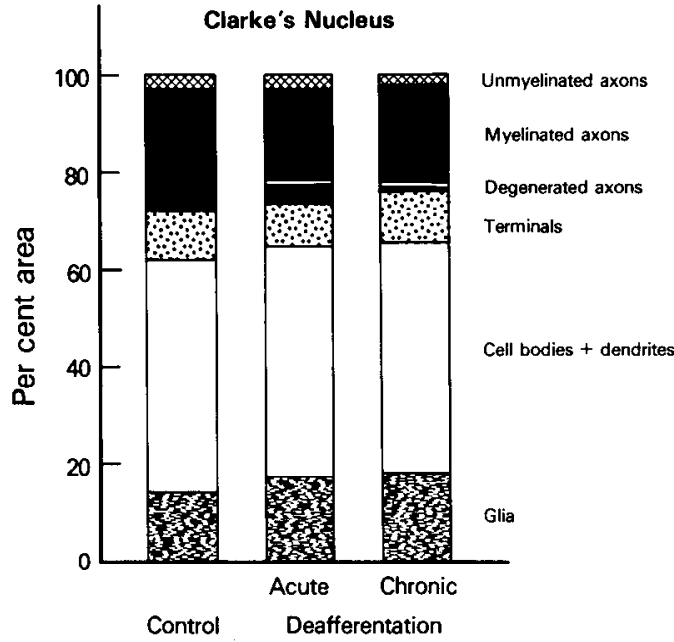

Figure 6. Composition of neuropil. Histograms summarizing data from Clarke's nucleus (for details see legend to Fig. 2). Note decreased area occupied by axons and increased area occupied by glial cytoplasm in deafferented groups. Area occupied by terminals shows slight decrease in acute deafferented group.

nals were seen only rarely and unoccupied postsynaptic sites were never seen. The few instances of dense terminal degeneration were restricted to terminals with spherical vesicles (Fig. 8). No degenerating axons or terminals were seen contralaterally.

In the acutely deafferented Clarke's nucleus, the synaptic population differed from control Clarke's nucleus in that the mean size of the terminals and the percentage of terminals containing spherical vesicles were both slightly decreased (Table 7). These observations are consistent with a loss of the large terminals containing spherical vesicles, as well as some smaller terminals with spherical vesicles.

Chronic. The synaptic population in the chronically deafferented Clarke's nucleus differed very little from control Clarke's nucleus. Both the mean size of terminals and the percentage of terminals containing spherical vesicles returned to normal. No changes were seen in other parameters (perimeter : area ratio, length of postsynaptic density).

\section{Estimate of terminal number in Clarke's nucleus}

Terminal number in Clarke's nucleus was estimated in the same way as in lamina II (Table 8 ). The total number of terminals shows a slight decrease that is not statistically significant in the acute period and returns to control levels in chronic survivors.
Table 5. Cross-sectional area of Clarke's nucleus

\begin{tabular}{lll} 
Group & $n$ & $\begin{array}{l}\text { Nuclear area } \\
\left(\mu \mathrm{m}^{2} \times 10^{4}\right)\end{array}$ \\
\hline Control & 7 & $17.9 \pm 1.9$ \\
Acute deafferentation & 4 & $17.8 \pm 2.0$ \\
Chronic deafferentation & 4 & $19.0 \pm 1.5$ \\
\hline
\end{tabular}

The fact that numbers of terminals are conserved indicates that synaptic terminals removed by rhizotomy are replaced and that the postsynaptic cells do not remain denervated. The replacement of terminals may not be completed during the $6 \mathrm{~d}$ acute period since during this time both terminal number and the percentage of terminals containing spherical vesicles were decreased. Synaptic replacement in Clarke's nucleus may therefore be somewhat delayed compared to the replacement of terminals in lamina II. The replacement terminals appear to share morphological (size, type of vesicle) characteristics with those that were lost.

\section{Discussion}

\section{Extent of synaptic replacement}

Our results indicate that removal of a major input to the cat spinal cord by dorsal rhizotomy elicits a replacement of lost synaptic terminals (reactive reinnervation) that is virtually complete. The increased density of intact projections (sprouting) we have demonstrated with light-microscopic methods after the same lesion (Goldberger and Murray, 1974, 1978, 1982; Tessler et al., 1980,1981, 1984) is thus associated with the formation of new synaptic contacts. Replacement of synaptic terminals studied with quantitative electron-microscopic methods has also been observed in the hippocampus (reviewed in Cotman et al., 1981; McWilliams and Lynch, 1984), septal nuclei (Field and Raisman, 1983; Raisman, 1969), red nucleus (Murakami et al., 1982; Tsukahara, 1978), and the interpeduncular nucleus (Murray et al., 1979); in some of these areas the recovery of synaptic number has also been virtually complete (Field and Raisman, 1983; McWilliams and Lynch, 1984). Our results and the results of other quantitative studies therefore indicate that reactive reinnervation restores the preoperative extent of innervation and also imply that the number of synaptic contacts is regulated by the postsynaptic cell (Lewis and Cotman, 1980; Murray et al., 1982).

Light-microscopic studies similar to those carried out in the

Table 4. Terminal number in lamina II

\begin{tabular}{|c|c|c|c|c|c|c|c|c|}
\hline Group & $n$ & $\begin{array}{l}\text { Cross- } \\
\text { sectional } \\
\text { area of } \\
\text { lamina } \mathrm{II}^{a} \\
\left(\mu \mathrm{m}^{2} \times 10^{4}\right)\end{array}$ & $\begin{array}{l}\text { Area } \\
\text { occupied } \\
\text { by termi- } \\
\text { nals }^{b}(\%)\end{array}$ & $\begin{array}{l}\text { Total area } \\
\text { occupied } \\
\text { by terminals } \\
\left(\mu \mathrm{m}^{2} \times 10^{4}\right)\end{array}$ & $\begin{array}{l}\text { Cross- } \\
\text { sectional } \\
\text { area of } \\
\text { terminals } \\
\left(\mu \mathrm{m}^{2}\right)\end{array}$ & $\begin{array}{l}\text { Total terminals } \\
\text { in cross section } \\
\text { of lamina } \\
\left(\times 10^{4}\right)\end{array}$ & $\begin{array}{l}\text { Synaptic } \\
\text { index }^{c}\end{array}$ & $\begin{array}{l}\text { Synaptic } \\
\text { contacts in } \\
\text { cross section } \\
\text { of lamina II } \\
\left(n \times 10^{4}\right)\end{array}$ \\
\hline Control & 9 & 19.2 & 14.5 & $2.75 \pm 0.20$ & 0.966 & $2.85 \pm 0.30$ & 1.38 & $4.07 \pm 0.37$ \\
\hline Acute deafferentation & & & & & & & & \\
\hline (3-5 d p.o.) & 5 & 17.8 & 12.3 & $2.33 \pm 0.26$ & $0.776^{d}$ & $3.02 \pm 0.48$ & $1.14^{d}$ & $3.46 \pm 0.52$ \\
\hline Chronic deafferentation & & & & & & & & \\
\hline (3-15 mo. p.o.) & 4 & 19.7 & $11.0^{d}$ & $2.18 \pm 0.23$ & $0.731^{d}$ & $2.99 \pm 0.29$ & $1.14^{d}$ & $3.39 \pm 0.30^{d}$ \\
\hline
\end{tabular}

Means or means \pm SEM are given.

a From Table 1.

${ }^{b}$ From Table 2.

c From Table 3.

${ }^{\star}$ Significantly different from control $(p<0.05)$. 

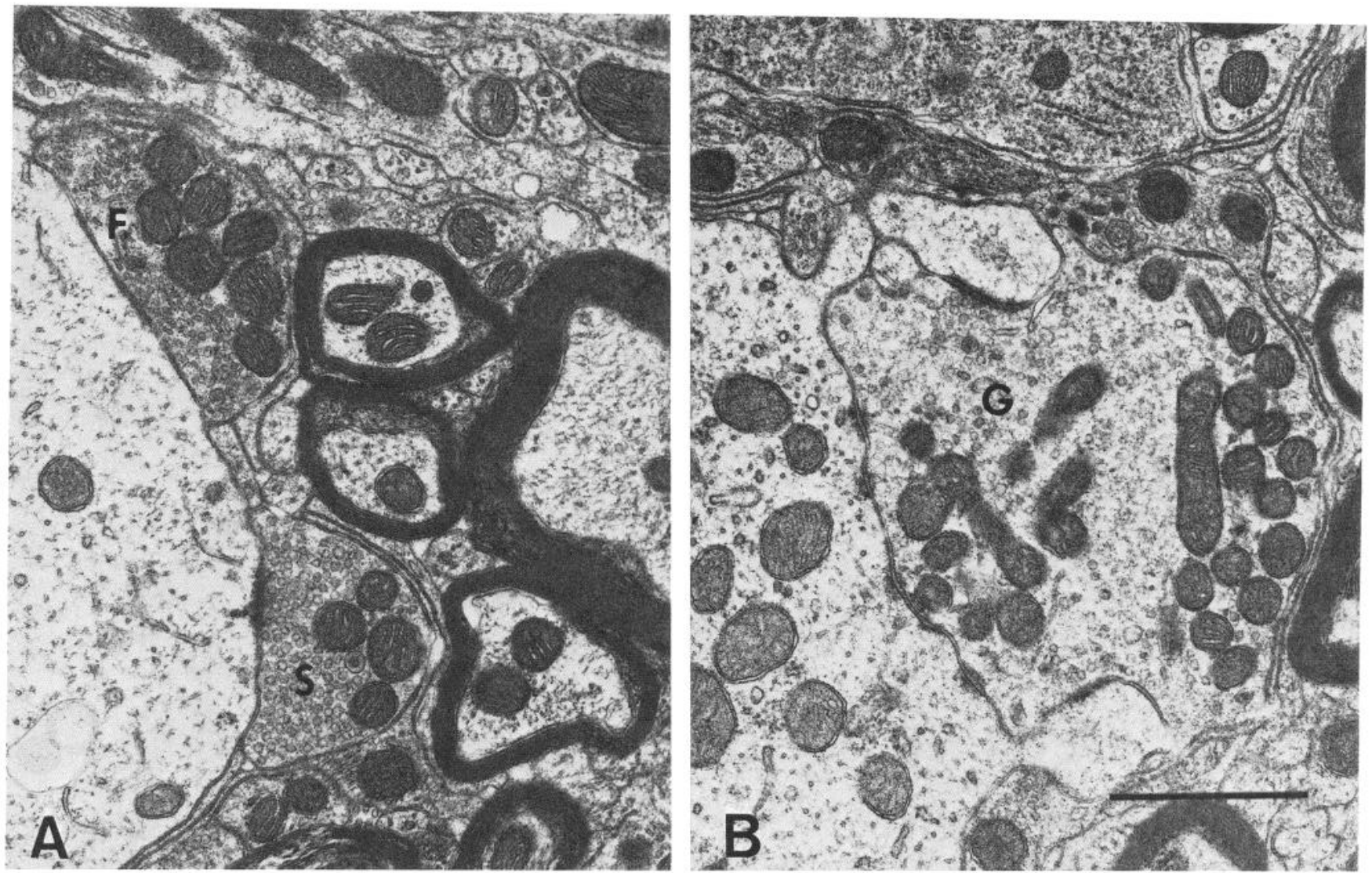

Figure 7. Electron micrographs from control Clarke's nucleus. Calibration bar, $1 \mu \mathrm{m}$. $A$, Small terminal with spherical vesicles $(S)$ and small terminal with flattened vesicles $(F)$ contacting postsynaptic structure. $B$, Large ("giant," $G$ ) axon terminal containing spherical vesicles. Note presence of several active zones.

cat have failed to provide evidence of sprouting in adult rat spinal cord with either degeneration methods (Stelzner et al., 1979) or transport methods (Rodin and Kruger, 1984; Rodin et al., 1983). These negative results have been interpreted to indicate not only that sprouting fails to occur in the adult rat cord (Rodin and Kruger, 1984; Rodin et al., 1983; Wall, 1984), but also that the evidence for sprouting in cat spinal cord is erroneous. Since the question of spinal cord sprouting is important, the reasons for these disparate results in rat and cat require consideration. Sprouting has been described in both rat and cat brain (reviewed in Cotman et al., 1981), so there does not appear to be a qualitative difference in the capability of the cat and rat central neurons to sprout. The failure of dorsal roots to sprout in the rat, however, does not preclude other systems, i.e., interneurons and descending tracts, from doing so. If, as we have suggested (Goldberger and Murray, 1978), there is a hierarchical control of sprouting, then the hierarchical order might be different in different species depending on the anatomical organization of the spinal cord. Differences in the response to partial deafferentation in the 2 species may reflect differences in anatomical organization, e.g., differences in the organization of dorsal root projections. Comparison of lumbar dorsal root projections in rat (Rodin and Kruger, 1984; Rodin et al., 1983) and cat (Goldberger and Murray, 1982) suggests that the terminal field of adjacent dorsal roots in the cat may exhibit greater overlap than in the rat. In the cat, dorsal roots maintain dense projections to one part of the dorsal horn and project more sparsely to other parts of the dorsal horn. The sparse projection of one dorsal root overlaps with the dense projection of its neighbor. This overlap appears to be less extensive in the rat, in which the dorsal root projections seem to be more sharply localized within the dorsal horn (Rodin and Kruger, 1984). Physiological differences also exist. The response in rats to partial rhizotomy includes an "immediate" change in receptive

Table 6. Composition of Clarke's nucleus (\% of area)

\begin{tabular}{|c|c|c|c|c|c|c|c|}
\hline Group & $n$ & $\begin{array}{l}\text { Myelinated } \\
\text { axons }\end{array}$ & $\begin{array}{l}\text { Unmyelinated } \\
\text { axons }\end{array}$ & $\begin{array}{l}\text { Degenerated } \\
\text { axons }\end{array}$ & Terminals & $\begin{array}{l}\text { Perikarya, } \\
\text { dendrites }\end{array}$ & $\begin{array}{l}\text { Non-neuronal } \\
\text { structures }\end{array}$ \\
\hline Control & 8 & $25.1 \pm 1.3$ & $2.4 \pm 0.9$ & 0 & $9.8 \pm 0.5$ & $49.3 \pm 2.8$ & $13.3 \pm 1.5$ \\
\hline \multicolumn{8}{|c|}{ Acute deafferentation } \\
\hline (3-6 d p.o.) & 4 & $19.7 \pm 1.9^{a}$ & $2.7 \pm 1.6$ & $4.3 \pm 1.1^{a}$ & $7.8 \pm 0.8^{a}$ & $47.3 \pm 3.9$ & $18.1 \pm 0.7^{a}$ \\
\hline \multicolumn{8}{|c|}{ Chronic deafferentation } \\
\hline (3-15 mo. p.o.) & 4 & $21.7 \pm 1.6^{a}$ & $2.2 \pm 0.9$ & $1.3 \pm 0.9^{a}$ & $9.5 \pm 1.4$ & $47.2 \pm 3.2$ & $18.0 \pm 1.9^{a}$ \\
\hline
\end{tabular}

Means \pm SEM are given.

a Significantly different from control $(p<0.05)$. 
field organization which is consistent with unmasking of latent synapses (Dostrovsky et al., 1976). Comparable receptive field changes are observed in the cat but develop over a much longer period (Mendell et al., 1978). The longer time course for receptive field change in the cat is consistent with a number of mechanisms, including sprouting. Although the mechanisms underlying these receptive field changes are not certain, the difference in time course probably reflects differences in anatomical organization of dorsal root projections in rat and cat.

\section{Time course of synaptic replacement of terminals}

The observation that terminal number does not decrease in lamina II after partial denervation suggests either that the replacement is almost instantaneous or that the denervation cannot be detected with the methods used. The methods used to estimate terminal number in the dorsal horn after dorsal rhizotomy were identical to those used in studying the goldfish optic tectum after optic nerve lesions (Murray and Edwards, 1982). In the goldfish a decrease in terminal number could be detected due to the long time between denervation and restoration of normal terminal number. The importance of those results for the present study is that they demonstrate that both the loss and recovery of synaptic complement can be detected with these methods. Furthermore, the area fraction of the dorsal root input to lamina II is at least equal to the area fraction occupied by retinal terminals in the goldfish optic tectum. The recovery of terminal number is, in both cases, virtually complete. The spinal cord differs from the goldfish tectum in that a fall in terminal number is not detected after complete lumbosacral dorsal rhizotomy. Our conclusion therefore is that sprouting, leading to reinnervation in the dorsal horn, is very rapid, perhaps overlapping temporally with the period of degeneration of primary afferent terminals.

In Clarke's nucleus there was a slight decrease in terminal number after deafferentation that was not significant. Our measurements of terminals in the control nucleus indicate that "giant" terminals that are believed to arise from the dorsal roots ( $\mathrm{Re}$ thelyi, 1970; Saito, 1979; Tracey and Walmsley, 1984) do not represent a distinct population of those terminals containing spherical vesicles. It is not possible, therefore, to show a loss of a specific population of terminals in Clarke's nucleus as it is for lamina II. If the dorsal root afferents contributed only a small percentage of the total number of terminals in Clarke's nucleus, then the loss might not be detectable by our methods. This possibility, however, seems unlikely; the density of the lumbosacral projections to Clarke's nucleus, as seen in the light microscope ("so dense as to defy minute analysis," Sprague and $\mathrm{Ha}, 1964)$ suggests that a substantial number of the terminals in Clarke's nucleus must be of dorsal root origin. The preservation of terminal number after deafferentation is probably due, in Clarke's nucleus as in lamina II, to a rapid replacement of dorsal root terminals by terminals containing spherical vesicles.

The time course of reactive reinnervation appears to vary

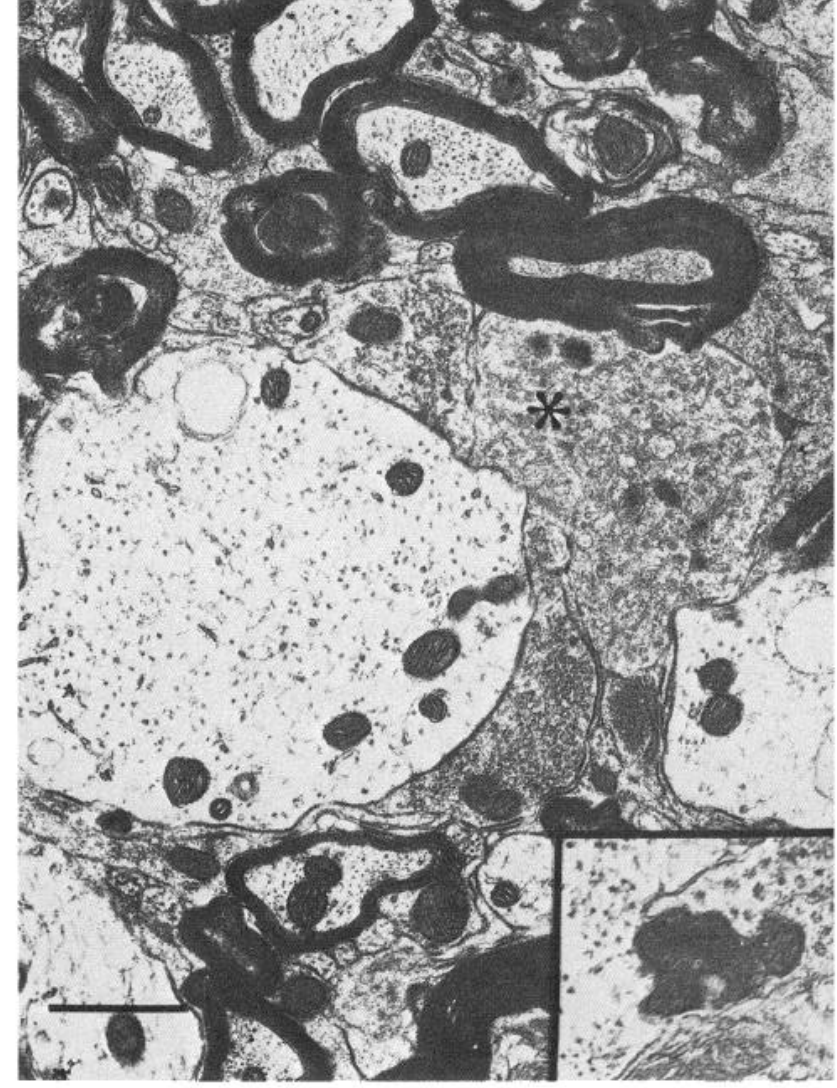

Figure 8. Electron micrograph showing examples of a dense degenerating terminal in Clarke's nucleus and a putative degenerating terminal characterized by irregular and swollen vesicles. Four days postoperative. Calibration bar, $1 \mu \mathrm{m}$.

considerably. In the cerebellum (Chen and Hillman, 1982) and lamina II, the reinnervation is extremely rapid, perhaps contemporaneous with degeneration. In hippocampus, reinnervation can be demonstrated after a 5 d latency (Lynch et al., 1982; McWilliams and Lynch, 1979, 1983). In the septum, reinnervation begins within the first week after unilateral fimbrial lesions but later after bilateral lesions (Field and Raisman, 1983). Many months, however, are required before interneurons reinnervate spinal motor neurons after spinal hemisection (Pullen and Sears, 1978, 1983). Finally, cholinergic and catecholaminergic projections in the hippocampus replace lesioned pathways by longdistance growth over a time course of several months (Gage et al., 1983); whether the hippocampal target cells remain denervated during this time is unknown. A prolonged period of denervation followed by reinnervation suggests interactions among intact converging systems in which some specific characteristic

Table 7. Synaptic terminals in Clarke's nucleus

\begin{tabular}{|c|c|c|c|c|c|c|c|}
\hline \multirow[b]{2}{*}{ Group } & \multirow[b]{2}{*}{$n$} & \multirow{2}{*}{$\begin{array}{l}\text { Cross-sectional } \\
\text { area of terminal } \\
\left(\mu \mathrm{m}^{2}\right)\end{array}$} & \multicolumn{2}{|c|}{ Vesical type (\%) } & \multicolumn{3}{|c|}{ Postsynaptic structure (\%) } \\
\hline & & & Spherical & Pleomorphic & Axodendritic & Axosomatic & Axoaxonic \\
\hline Control & 7 & $1.82 \pm 0.13$ & $78.4 \pm 7.6$ & $21.5 \pm 7.5$ & $84.1 \pm 6.4$ & $15.0 \pm 6.1$ & $2.5 \pm 2.0$ \\
\hline \multicolumn{8}{|l|}{ Acute deafferentation } \\
\hline (3-6 d p.o.) & 4 & $1.55 \pm 0.12^{a}$ & $65.6 \pm 8.5$ & $34.4 \pm 8.5^{a}$ & $89.8 \pm 8.1$ & $8.8 \pm 8.2$ & $0^{a}$ \\
\hline \multicolumn{8}{|l|}{ Chronic deafferentation } \\
\hline (3-15 mo. p.o.) & 4 & $1.73 \pm 0.20$ & $72.7 \pm 8.7$ & $27.3 \pm 4.3$ & $89.9 \pm 5.9$ & $9.9 \pm 6.2$ & $0.4 \pm 0.5$ \\
\hline
\end{tabular}

Means \pm SEM are given.

a Significantly different from control $(p<0.05)$. 
Table 8. Terminal number in Clarke's nucleus

\begin{tabular}{|c|c|c|c|c|c|c|}
\hline Group & $n$ & $\begin{array}{l}\text { Cross-sec- } \\
\text { tional area } \\
\text { of nucleus } \\
\left(\mu \mathrm{m}^{2} \times 10^{4}\right)\end{array}$ & $\begin{array}{l}\text { Area of } \\
\text { nucleus } \\
\text { occupied } \\
\text { by termi- } \\
\text { nals }^{b}(\%)\end{array}$ & $\begin{array}{l}\text { Total area } \\
\text { occupied } \\
\text { by terminals } \\
\left(\mu \mathrm{m}^{2} \times 10^{4}\right)\end{array}$ & $\begin{array}{l}\text { Cross- } \\
\text { sectional } \\
\text { area of } \\
\text { terminals } \\
\left(\mu \mathrm{m}^{2}\right)\end{array}$ & $\begin{array}{l}\text { Total terminals } \\
\text { in cross section } \\
\text { of nucleus } \\
\left(\times 10^{4}\right)\end{array}$ \\
\hline Control & 7 & 17.9 & 9.8 & $1.75 \pm 0.13$ & 1.82 & $1.00 \pm 0.09$ \\
\hline Acute deafferentation (3-6 d p.o.) & 4 & 17.8 & $7.8^{d}$ & $1.38 \pm 0.14^{d}$ & $1.55^{d}$ & $0.92 \perp 0.01$ \\
\hline Chronic deafferentation (3-15 mo. p.o.) & 4 & 19.0 & 9.5 & $1.78 \pm 0.27$ & 1.73 & $1.04 \pm 0.18$ \\
\hline
\end{tabular}

Means or means \pm SEM are given.

${ }^{a}$ From Table 1 .

${ }^{b}$ From Table 6.

${ }^{c}$ From Table 7.

${ }^{d}$ Significantly different from control $(p<0.05)$.

of the successful system determines the outcome, as has been shown in the regenerating goldfish visual system (Edwards and Murray, 1985; Edwards et al., 1985; Murray and Edwards, 1982; Murray et al., 1982). These different time courses emphasize that more than one factor may play a role in the reinnervation process and that the relative importance of these factors may vary from one neuronal system to another.

\section{Specificity of synaptic replacement}

One type of interaction for which there is evidence from several systems is a hierarchical regulation that determines which of several available systems can form persistent sprouts (Cotman et al., 1981; Field and Raisman, 1983; Goldberger and Murray, 1978). The basis of this regulation is uncertain. One hypothesis, consistent with a hierarchical control and with maximal retention of specificity, attributes a competitive advantage to those intact systems most closely resembling the lesioned axons ("homotypic" sprouting). Similarity in neurotransmitter (or modulator) contained by the lost axons and those that sprout may be one such regulatory factor. In lamina II, it is unlikely that the replacement terminals at L6 derive from dorsal root axons, either from the contralateral side or from the remaining thoracic roots. The replacement terminals therefore arise from central neurons. We do know that the large terminals with spherical vesicles are replaced by small terminals with spherical vesicles. Many large "scalloped" or central terminals are of dorsal root origin (Coimbra et al., 1974; Knyihar and Csillik, 1976; Knyihar-Csillik and Csillik, 1981; Ralston, 1968; Ralston and Ralston, 1979; Snyder, 1982); some contain substance P (SP) (deLancrollc and Lamotte, 1983), as do some small terminals (Hunt et al., 1980; deLanerolle and Lamotte, 1983; Pickel et al., 1977). Tessler et al. $(1980,1981,1984)$ concluded that the SP lost after deafferentation is replaced by sprouting of SPcontaining interneurons. Some of the small profiles that replace the large central terminals may be sprouted SP-containing interneuronal terminals, and they could represent an instance of homotypic sprouting. The replacement of SP is incomplete, however (Tessler et al., 1984), and other sources of replacement terminals may be anticipated. Preliminary light-microscopic immunocytochemical evidence (Goldberger et al., 1985) indicates that 5-HT-containing axons may provide an additional source for replacement terminals in lamina II. Replacement of lost innervation by serotonergic terminals would suggest heterotypic sprouting since 5 -HT has not been identified in primary afferents of the cat (as has been suggested for the rat; see Di Carlo, 1983). The conclusions that we can draw from these analyses, however, are at present limited by the nonquantitative nature of immunocytochemical labeling methods at the electron-microscopic level.

Clarke's nucleus has received less attention than lamina II, but it appears to be organized more simply and with less con- vergence of heterogeneous systems than the dorsal horn (Mann, 1973). As in lamina II, however, we cannot characterize the replacement terminals aside from noting that they contain spherical vesicles. The presence, in the chronically deafferented Clarke's nuclei, of large terminals suggests that one source of the reinnervation may be the lowest remaining dorsal roots. The decrease in terminal area observed acutely suggests that thoracic dorsal root terminals in L3 Clarke's nucleus are normally small in number and/or size and are induced to increase in number and size by the degeneration of other dorsal root afferents. The extent to which the caudal thoracic dorsal roots normally project to L3 may be quite small and not sufficient to account entirely for the replacement of the dorsal root afferents removed by the lesion. Alternatively, reinnervation by caudal thoracic roots could represent a caudal extension of this innervation; for several reasons (see Goldberger and Murray, 1978) this seems less likely.

Our evidence, while circumstantial and incomplete, is consistent with homotypic reinnervation in both lamina II and Clarke's nucleus and some heterotypic sprouting in lamina II. Lesion-induced sprouting is not always homolypic, i.e., is not always associated with a strict conservation of neurochemical specificity (Battisti et al., 1984; Crutcher and Davis, 1981; Gage et al., 1983; Goldberger et al., 1985; Loy and Moore, 1977). In fact, sprouting, since it represents a reorganization of the synaptic pattern formed during development, may be considered to violate the strictest laws of specificity.

\section{Changes in postsynaptic structures after deafferentation}

Deafferentation might be expected to produce changes in the partially denervated postsynaptic cells. A significant atrophy of postsynaptic structures does occur in goldfish tectum after optic nerve crush, and this effect is reversed when the regenerating axons re-enter the tectum (Murray and Edwards, 1982). Permanent shrinkage and distortion of the dendritic branching patterns have been demonstrated in Clarke's neurons of cats deafferented as kittens but not when the same lesion was performed in adults (Liu, 1954; Loewy, 1972; Smith, 1974). A persisting transneuronally induced atrophy limited to distal dendrites has also been described for Golgi-impregnated neurons in laminae IV-VI following dorsal root section in adult cat (Brown et al., 1979) and cavitation of the most distal dendrites occurred after peripheral nerve lesion, although not after dorsal root lesion, in the medullary dorsal horn of adult cat (Gobel, 1984). In contrast, Mendell et al. (1986) described a modest hypertrophy of ventral spinocervical cell dendrites after partial deafferentation; these cells also developed an increased probability of responding to thermal or noxious stimuli, which could be attributable to sprouting or to denervation supersensitivity.

Our stereological analysis of postsynaptic structures does not distinguish between distal and proximal dendrites and perikarya but was nevertheless sensitive enough to detect a shrinkage of 
postsynaptic structures in fish. The absence of a statistically significant change in area occupied by postsynaptic changes in the cat material may indicate that those postsynaptic changes that occur are quite specifically localized, perhaps to distal dendrites, and thus quantitatively too limited to be detectable using our methods. It is also possible that atrophic changes in the fish developed because of the prolonged period of denervation, while the rapid reinnervation in lamina II and Clarke's nucleus prevented the development of marked transneuronal atrophy.

\section{Recovery of motor function after dorsal rhizotomy}

It is interesting to compare the morphological sequellae of deatferentation with recovery of motor function after the same lesion. After lumbosacral dorsal rhizotomy (or ganglionectomy), an initial paralysis is followed by a rapid ( 1 or $2 \mathrm{~d}$ ) recovery of gross, poorly controlled locomotion (Goldberger and Murray, 1974) as the spinal pattern generator for locomotion (Grillner, 1981, for review) emerges from the acute effects of denervation, e.g., spinal shock. The recovery of accurate limb placement during locomotion appears only at the end of the first week (Goldberger, 1977). Quantitative aspects of the gait of the deafferented limb are different for free locomotion and for accurate locomotion (Goldberger and Olivier, 1984), whereas the normal cat hindlimb displays comparable kinematic patterns for both free and accurate locomotion. The recovery of these 2 different facets of motor function (free and accurate locomotion) may thus be mediated by different pathways. Most of the recovery takes place during the first postoperative week, the same period during which most of the reinnervation takes place. The time course for replacement in lamina II is extremely rapid; that in Clarke's nucleus may be somewhat more delayed. These different time courses may be analogous to the different time courses observed for recovery of motor functions. Synaptic replacement, although virtually complete, does not result in a normal synaptic complement since, in lamina II, large terminals with several contacts are replaced by small ones making a single contact and the source of the replaced input is not the normal one. The movements recovered are also different from normal. We have studied 2 spinal cord regions whose relationship to motor output is indirect. This does not imply that the return of motor function is mediated by synaptic replacement in these regions. Rather, these are examples of compensatory processes that are likely to contribute to the recovery.

\section{References}

Battisti, W., B. Levin, and M. Murray (1984) Norepinephrine in the IPN: Effects of locus coeruleus lesion. Soc. Neurosci. Abstr. 10: 1022.

Brown, P. B., G. R. Busch, and J. Whittington (1979) Anatomical changes in cat dorsal horn cells after transection of a single dorsal root. Exp. Neurol. 64: 453-468.

Chen, S., and D. E. Hillman (1982) Plasticity of the parallel fiberPurkinje cell synapse by spine takeover and new synapse formation in the adult rat. Brain Res. 240: 205-220.

Chow, K. L., L. H. Ostrach, J. W. Crabtree, O. Bernegger, H. D. Braumbach, and R. Lawson (1981) Anomalous uncrossed retinal projections fail to activate superior colliculus neurons in rabbits unilaterally enucleated by fetal surgery. J. Comp. Neurol. 196: 189-204.

Coimbra, A., B. P. Sodre-Borges, and M. M. Magalhaes (1974) The substantia gelatinosa Rolandi of the rat. Fine structure, cytochemistry (acid phosphatase) and changes after dorsal root section. J. Neurocytol. 3: 199-217.

Cotman, C. W., M. Nieto-Sampedro, and E. W. Harris (1981) Synapse replacement in the nervous system of adult vertebrates. Physiol. Rev. 61: 644-782.

Crutcher, K. A., and J. N. Davis (1981) Sympathetic noradrenergic response to central cholinergic denervation. Trends Neurosci. 4: 7072

Devor, M., A. I. Basbaum, and Z. Seltzer (1986) Spinal somatotopic plasticity: Possible anatomical basis for somatotopically inappropriate connections. In Development and Plasticity of the Mammalian
Spinal Cord, M. E. Goldberger, A. Gorio, and M. Murray, eds., pp. 211-227, Liviana, Padova, Italy.

Di Carlo, V. (1983) Serotonergic fibers in dorsal roots of the spinal cord. Neurosci. Lett. 43: 119-125.

Dostrovsky, J. O., G. Millar, and P. D. Wall (1976) The immediate shift of afferent drive of dorsal column nucleus cells following deafferentation. A comparison of acute and chronic deafferentation in gracile nucleus and spinal cord. Exp. Neurol. 52: 480-495.

Ebbesson, S. O. E., and K. Rubinson (1969) A simplified Nauta procedure. Physiol. Bchav. 4: 281-282.

Edwards, M., and M. Murray (1985) Selective retinal reinnervation of a surgically created tectal island in goldfish. II. Electron microscopic analysis. J. Comp. Neurol. 232: 386-400.

Edwards, M. A., S. C. Sharma, and M. Murray (1985) Selective retinal innervation of a surgically created tectal island in goldfish. I. Light microscopic analysis. J. Comp. Neurol. 232: 372-385.

Field, P. M., and G. Raisman (1983) Relative slowness of heterotypic synaptogenesis in septal nuclei. Brain Res. 272: 83-99.

Gage, F. H., A. Bjorklund, and U. Stenevi (1983) Reinnervation of the partially deafferented hippocampus by compensatory collateral sprouting from spared cholinergic and noradrenergic afferents. Brain Res. 268: 27-37.

Gobel, S. (1984) An electron microscopic analysis of the trans-synaptic effects of peripheral nerve injury subscquent to tooth pulp extirpations on neurons in laminae I and II of the medullary dorsal horn. J. Neurosci. 4: 2281-2290.

Goldberger, M. E. (1977) Locomotor recovery after unilateral hindlimb deafferentation in cats. Brain Res. 123: 59-74.

Goldberger, M. E. (1981) The role sprouting might play during recovery of function. In Lesion-Induced Neuronal Plasticity in Sensorimotor Systems, H. Flohr and W. Precht, eds., pp. 130-140, SpringerVerlag, New York.

Goldberger, M. E., and M. Murray (1974) Restitution of function and collateral sprouting in cat spinal cord: The deafferented animal. J. Comp. Neurol. 158: 37-57.

Goldberger, M. E., and M. Murray (1978) Axonal sprouting and recovery of function may obey some of the same laws. In Neuronal Plasticity, C. Cotman, ed., pp. 73-96, Raven, New York.

Goldberger, M. E., and M. Murray (1982) Lack of sprouting and its presence after lesions of the cat spinal cord. Brain Res. 241: 227239

Goldberger, M. E., and M. Murray (1985) Recovery of function and anatomical plasticity after damage to the adult and neonatal spinal cord. In Synaptic Plasticity, C. Cotman, ed., pp. 77-110, Guilford, New York.

Goldberger, M. E., and J. Olivier (1984) Locomotor patterns during recovery in cats after complete or partial hindlimb deafferentation. Anat. Rec. 208: 63A.

Goldberger, M. E., E. Coleman, and S. Segal (1985) Plasticity in the serotonin (5HT) system of the cat spinal cord. Anat. Rec. $211: 70 \mathrm{~A}$.

Grillner, S. (1981) Control of locomotion in bipeds, tetrapods and fish. In Handbook of Physiology, Vol. 2, V. B. Brooks, ed., pp. 11791236.

Heimer, L., and P. D. Wall (1968) The dorsal root distribution to the substantia gelatinosa of the rat with a note on the distribution in the cat. Exp. Brain Res. 6: 89-99.

Hunt, S. P., J. S. Kelly, and P. C. Emson (1980) The electron microscopic localization of methionine enkephalin within the superficial layers (I and II) of the spinal cord. Neuroscience 5: 1871-1890.

Jackson, P. C., and J. Diamond (1983) Failure of intact cutaneous mechanosensory axons to sprout functional collaterals in skin of adult rabbits. Brain Res. 273: 277-283.

Kerr, F. W. L. (1972) The potential of cervical primary afferents to sprout into the sensory nucleus of $\mathrm{V}$ following long term trigeminal denervation. Brain Res. 43: 547-560.

Knyihar, E., and B. Csillik (1976) The effect of peripheral axotomy on the fine structure and histochemistry of the Rolando substance: Degenerative atrophy of central processes of pseudounipolar cells. Exp. Brain Res. 26: 73-87.

Knyihar-Csillik, E., and B. Csillik (1981) Selective "labelling" by transsynaptic degeneration of substantia gelatinosal cells: An attempt to decipher intrinsic wiring in the Rolando substance of primates. Neurosci. Lett. 23: 131-136.

deLanerolle, N. C., and C. C. Lamotte (1983) Ultrastructure of chemically defined neuron systems in the dorsal horn of the monkey. I. Substance P immunoreactivity. Brain Res. 274: 31-49. 
Lewis, E. R., and C. W. Cotman (1980) Factors specifying the development of synapse number in the rat dentate gyrus: Effects of partial target loss. Brain Res. 191: 35-52.

Liu, C. N. (1954) Study of the innervation of Clarke's nucleus in the cat. Anat. Rec. 118: 326.

Liu, C. N., and W. W. Chambers (1958) Intraspinal sprouting of dorsal root axons. Arch. Neurol. Psychiatr. 79: 46-61.

Loesche, J., and O. Steward (1977) Behavioral correlates of denervation and reinnervation of the hippocampal formation of the rat. Brain Res. Bull. 2: 31-39.

Loewy, A. D. (1972) The effects of dorsal root lesions on Clarke's nucleus in cats of different ages. J. Comp. Neurol. 145: 141-164.

Loy, R., and R. Y. Moore (1977) Anomalous innervation of the hippocampal formation by peripheral sympathetic axons following mechanical injury. Exp. Neurol. 57: 645-650.

Lynch, G., J. R. McWilliams, and C. Gall (1982) The effects of successive lesions on the time course of the sprouting response in the hippocampus of the rat. Brain Res. 240: 154-157.

Mann, M. D. (1973) Clarke's column and the dorsal spinocerebellar tract: A review. Brain Behav. Evol. 7: 34-83.

McWilliams, R., and G. Lynch (1979) Terminal proliferation in the partially deafferented dentate gyrus: Time course for appearance and removal of degeneration and the replacement of lost terminals. J. Comp. Neurol. 187: 191-198.

McWilliams, J. R., and G. Lynch (1983) Rate of synaptic replacement in denervated rat hippocampus declines precipitously from the juvenile period to adulthood. Science $221: 572-574$.

McWilliams, J. R., and G. Lynch (1984) Synaptic density and axonal sprouting in rat hippocampus: Stability in adulthood and decline in late adulthood. Brain Res. 294: 152-156.

Mendell, L. M., E. M. Sassoon, and P. D. Wall (1978) Properties of synaptic linkage from long-ranging afferents onto dorsal horn neurons in normal and deafferented cats. J. Physiol. (Lond.) 285: 299-310.

Mendell, L. M., M. J. Sedivec, and R. J. Traub (1986) Response of an identified population of spinal cord neurons to partial deafferentation. In Development and Plasticity of the Mammalian Spinal Cord, M. E. Goldberger, A. Gorio, and M. Murray, eds., pp.111-121, Liviana, Padova, Italy.

Murakami, F., H. Katsumaru, K. Saito, and N. Tsukahara (1982) A quantitative study of synaptic reorganization in red nucleus neurons after lesion of the $\mathrm{N}$. interpositus of the cat. Brain Res. 242: 41-53.

Murray, M., and M. Edwards (1982) A quantitative study of innervation of the goldfish optic tectum following optic nerve crush. J. Comp. Neurol. 209: 363-373.

Murray, M., and M. E. Goldberger (1974) Restitution of function and collateral sprouting in the cat spinal cord: The partially hemisected animal. J. Comp. Neurol. 158: 19-36.

Murray, M., J. Zimmer, and G. Raisman (1979) Quantitative electron microscopic evidence for reinnervation in the adult rat interpeduncular nucleus after lesions of the fasciculus retroflexus. J. Comp. Neurol. 187: 447-468.

Murray, M., S. Sharma, and M. A. Edwards (1982) Target regulation of synaptic number in the compressed retinotectal projection of goldfish. J. Comp. Neurol. 209: 374-385.

Murray, M., W. Battisti, and M. E. Goldberger (1983) Synaptic replacement in deafferented dorsal horn (Lamina II) of cat. Soc. Neurosci. Abstr. 9: 987.

Murray, M., W. Battisti, G. Liu, and M. E. Goldberger (1984) Synaptic replacement in Clarke's nucleus after lumbosacral rhizotomy. Soc. Neurosci. Abstr. 10: 1017.

Pickel, V. M., M. Segal, and F. M. Bloom (1974) Axonal proliferation following lesions of cerebellar peduncles: A combined fluorescence microscopic and radioautographic study. J. Comp. Neurol. 155: 4350.

Pickel, V. M., D. J. Reis, and S. E. Leeman (1977) Ultrastructural localization of substance $\mathrm{P}$ in neurons of rat spinal cord. Brain Res. 122: 534-540.

Pubols, L. M., and M. E. Goldberger (1980) Recovery of function in dorsal horn following partial deafferentation. J. Neurophys. 43: 102117.

Pullen, A. H., and T. A. Sears (1978) Modification of 'C' synapses following partial central deafferentation of thoracic motorneurons. Brain Res. 145: 141-146.

Pullen, A. H., and T. A. Sears (1983) Trophism between c-type axon terminals and thoracic motoneurones in the cat. J. Physiol. (Lond.) 337: 373-388.
Raisman, G. (1969) Neuronal plasticity in the septal nuclei of the adult rat. Brain Res. 14: 25-48.

Ralston, H. J. (1968) Dorsal root projections to dorsal horn neurons in the cat spinal cord. J. Comp. Neurol. 132: 309-330.

Ralston, H. J., and D. D. Ralston (1979) The distribution of dorsal root axons in laminae I, II, and III of the macaque spinal cord. A quantitative electron microscopic study. J. Comp. Neurol. 184: 643684.

Rethelyi, M. (1970) Ultrastructural synaptology of Clarke's column. Exp. Brain Res. 11: 159-174.

Ribeiro-da-Silva, A., and A. Coimbra (1984) Capsaicin causes selective damage to type I synaptic glomeruli in rat substantia gelatinosa. Brain Res. 290: 380-383.

Rodin, B. E., and L. Kruger (1984) Absence of intraspinal sprouting in dorsal root axons caudal to a partial spinal hemisection: A horseradish peroxidase transport study. Somatosensory Res. 2: 171-192.

Rodin, B. E., S. L. Sampogna, and L. Kruger (1983) An examination of intraspinal sprouting in dorsal root axons with the tracer horseradish peroxidase. J. Comp. Neurol. 215: 187-198.

Saito, K. (1979) Morphometrical synaptology of Clarke cells and of distal dendrites in the nucleus dorsalis: An electron microscopic study in the cat. Brain Res. 178: 233-249.

Schneider, G. E. (1970) Mechanisms of functional recovery following lesions of visual cortex or supcrior colliculus in neonate and adult hamsters. Brain Behav. Evol. 3: 295-323.

Smith, D. E. (1974) The effect of deafferentation on the postnatal development in Clarke's nucleus in the kitten. Brain Res. 74: 119130.

Snyder, R. L. (1982) Light and electron microscopic autoradiographic study of the dorsal root projections to the cat dorsal horn. Neuroscience 7: 1417-1437.

Sprague, J. M., and H. Ha (1964) The terminal fields of dorsal root fibers in the lumbosacral spinal cord of the cat and the dendritic organization of these nuclei. Prog. Brain Res. 11: 120-154.

Stelzner, D. J., E. D. Weber, and J. Prendergast (1979) A comparison of the effects of mid-thoracic hemisection in the neonatal or weanling rat on the distribution and density of dorsal root axons in the lumbosacral spinal cord of the adult. Brain Res. 172: 407-426.

Szentagothai, J. (1961) Somatotopic arrangement of synapses of primary sensory neurons in Clarke's column. Acta Morphol. Acad. Sci. Hung. 10: 307-311.

Tessler, A., E. Glazer, R. Artymyshyn, M. Murray, and M. E. Goldberger (1980) Recovery of substance $P$ in the cat spinal cord after unilateral lumbosacral deafferentation of cat spinal cord. Brain Res. 191: 459470.

Tessler, A., B. T. Himes, R. Artymyshyn, M. Murray, and M. E. Goldberger (1981) Spinal neurons mediate return of substance $\mathbf{P}$ following deafferentation of cat spinal cord. Brain Res. 230: 263-281.

Tessler, A., B. T. Himes, K. Soper, M. Murray, M. F. Goldberger, and S. Reichlin (1984) Recovery of substance P but not somatostatin in the cat spinal cord after unilateral lumbosacral dorsal rhizotomy: A quantitative study. Brain Res. 305: 95-102.

Thor, K. B., D. C. Kuo, W. C. deGroat, D. Blais, and M. Bachus (1982) Alteration of HRP-labelled pudendal nerve afferent projections in the sacral spinal cord of the cat during neonatal development and after spinal cord transection. Soc. Neurosci. Abstr. 8: 305.

Thor, K., M. Kawatani, and W. C. deGroat (1986) Plasticity in the reflex pathways to the lower urinary tract in the cat during postnatal development and following spinal cord injury. In Development and Plasticity of the Mammalian Spinal Cord, M. E. Goldberger, A. Gorio, and M. Murray, eds., pp. 65-81, Liviana, Padova, Italy.

Tracey, D. J., and B. Walmsley (1984) Synaptic input from identified muscle afferents to neurones of the dorsal spinocerebellar tract in cat. J. Physiol. (Lond.) 350: 599-604.

Tsukahara, N. (1978) Synaptic plasticity in the red nucleus. In Neuronal Plasticity, C. W. Cotman, ed., pp. 113-130, Raven, New York.

Tsukahara, N., H. Hultborn, F. Murakami, and Y. Fujito (1975) Electrophysiological study of formation of new synapses and collateral sprouting in red nucleus neurons after partial denervation. J. Neurophysiol. 38: 1359-1372.

Wall, P. D. (1984) The dorsal horn. In Textbook of Pain, P. D. Wall and R. Melzack, eds., pp. 80-87, Churchill Livingstone, New York.

Wu, L.-F., M. E. Goldberger, and M. Murray (1986) Dorsal root terminals in lamina II of cat spinal cord: Effects of partial deafferentation. Anat. Rec. 214: 147A. 